the author states: "In a large number of places and over fairly long lengths the irregularities are within the range of only $1 \mathrm{~mm}$; irregularities ranging between about $1 \mathrm{~mm}$ and $2 \mathrm{~mm}$ occur only over very short distances, and irregularities in excess of $3 \mathrm{~mm}$ are hardly present at all". The argument is impressive, but as tho author of this paper is careful to add: ". . . causes of irregularity of the concrete surface must be sought both in the constructional technique employed, i.e. the machines and their operation, and in failure to comply with the technological conditions applicable to any concrete used for pavement construetion".

\title{
PHYSICS AT EINDHOVEN
}

$\mathrm{T}$ HE oldest section of the Philips Research Laboratories was built at Eindhoven in 1924 in what was then a quiet rural district, but to-day it is hemmed in by the Philips factories and is surrounded by a busy town environment. The conditions are no longer suitable for advanced research work, and in 1958 it was decided to replace the Laboratories by a complex of new buildings in better surroundings. A site of about 275 acres at Waalre, a few kilometros south of Eindhoven, was obtained and buildings to accommodate a staff of some 3,000 by 1970 are to be built. The complex is to consist of four sectors, each sector comprising one large laboratory block. a workshop, subsidiary buildings for special experiments, a reading room, lecture theatre and canteen. There will be, in addition, at the centre of the site a building containing offices and general services, including a large restaurant, a central library and a spacious auditorium, suitable for large meetings and congresses. The laboratory block of the first sector has been completed and was recently taken into service. To mark the oceasion a symposium attended by a large number of distinguished guests representing research establishments in many countries was held at Waalre during September 26-27. Three main lectures wero given and fifty papers on specialized topies were read by members of the staff of the Laboratories.

The September issue of the Philips Technical Review $(24$, No. $11 / 12 ; 1963)$ is devoted to a description of the symposium, together with a photograph of the main eight-storey laboratory block and a descriptive article by M. J. Jansen Gration of the planning of the new complex of buildings. Prof. H. B. G. Casimir, the director of all the research activities of the Philips industries, gave a brief introductory address, and delivered the first lecture, entitled "Some Main Lines of 50 Years of Philips Research in Physics", in which he briefly reviewed various subjects of research at the Laboratories relating to gas discharges, ferromagnetism, solid-state physics and network theory. F. de Jager, in his lecture on "Modulation, Yesterday and Tomorrow", described how the everincreasing demands on communication links have led to the introduction of new methods of modulation. Frequency modulation, pulse-code modulation and delta modulation are discussed and, looking into the future, de Jager considered that during the next fifty years the combination of results found in information theory and in perception research will lead to the design of still more effective methods of modulation. The contributions of the Philips Research Laboratories to solid-state chemistry was the subject of the third main lecture, and $H$. J Vink briefly reviewed four areas of activity-crystal chemistry, internal charge compensation, gases and metals, and thermodynamies.

In addition to the texts of these talks, the Review contains summaries of the papers, and of the two demonstrations set up in the Laboratories. The papers are classified under four headings-fundamental, devices and materials, systems and measuring, and biochemistry and perception. The two demonstrations are of particular interest. The first, by $\mathrm{G}$. Prast, showed the recent application of a modification of the Philips-Stirling thermodynamic cycle which has enabled the production of a gas-refrigerating machine for the temperature of liquid hydrogen*. The addition of a Joule-Thomson circuit can extend the temperature range towards the helium region. The second demonstration, by E. F. de Haan and S. L. Tan, was of the 'Plumbicon', a pick-up tube similar to the 'Vidicon', but using the photoconductive properties of lead monoxide. A colour camera for television broadcasting using this tube has been constructed and is claimed to be four times more sensitive than a 3 -in. image 'Orthicon' colour eamera, with an improved signal-tonoise ratio and a higher range of contrast.

\section{S. WeINTROUB}

* A more detailed description has now been published in Cryogenics, 3 156 . September 1963.

\section{CARBIDES IN NUCLEAR ENERGY}

\begin{abstract}
$\mathrm{T}$ WO hundred and fifty delegates from eighteen countries attended a symposium held at the United Kingdom Atomic Energy Research Establishment, Harwell, during November $5-7$, at which sixty-seven papers were presented, dealing with many diverse aspects of the carbides of uranium, plutonium and thorium. The papers were divided into four separate sections, which were concerned with phase diagrams (Sessions 1 and 2), fabrication (Sessions 3 and 4), chemical and physical properties (Session 5), and irradiation behaviour (Session 6).

In the first two sessions, the earlier papers were concerned with features of the uranium-carbon diagram, the exact form of which remains in doubt. It was suggested by Magnier and Accary, of Saclay, that the shape of the uranium-rich boundary of the UC phase implies the existence of a phase of higher uranium content than UC. There seems to be little direct experimental evidence for this new phase, and some contributors to the discussion
\end{abstract}

were not convinced of its existence. Two papers dealt with the orientation relationships between $\mathrm{UC}_{2}$ and a parent UC matrix as determined by X-ray diffraction and electron diffraction and microscopy; the results were in good agreement. Imoto has shown that the hightemperature form of uranium dicarbide only exists for a carbon/uranium ratio less than $1 \cdot 86$, whereas the lowtemperature tetragonal form probably exists at the stoichiometric ratio.

Papers on plutonium-carbon alloys tended to confirm earlier work on the plutonium-carbon phase diagram and on the rate of self-irradiation damage of the various plutonium carbides; the complex behaviour of alloys with carbon contents between 40 and 50 atomic per cent, where $\mathrm{Pu}_{3} \mathrm{C}_{2}$ and $\mathrm{PuC}_{1-x}$ coexist, was also emphasized. Work on the uranium-plutonium-carbon system at carbon contents above $\mathbf{5 0}$ atomic per cent was described by Dalton, who has shown that the $M_{2} \mathrm{C}_{3}$ phase is rapidly 